Revised Manuscript to Bioresource Technology

\title{
Production of Jatropha Biodiesel Fuel over Sulfonic Acid-based Solid Acids
}

Shih-Yuan Chen ${ }^{a^{*}}$, Supranee Lao-ubol ${ }^{\mathrm{b}}$, Takehisa Mochizuki ${ }^{\mathrm{a}}$, Yohko Abe ${ }^{\mathrm{a}}$, Makoto

Toba $^{\mathrm{a}}$, Yuji Yoshimura ${ }^{\mathrm{a}}$

${ }^{a}$ Hydrotreating Catalysis Team, Research Center for New Fuels and Vehicle

Technology, National Institute of Advanced Industrial Science and Technology (AIST),

1-1-1 Higashi, Tsukuba, Ibaraki 305-8565, Japan.

${ }^{\mathrm{b}}$ Material Innovation Department, Thailand Institute of Scientific and Technological

Research (TISTR), 35 M 3, Klong 5, Klongluang, Pathumthani 12120, Thailand.

To whom correspondence should be addressed:

Shih-Yuan Chen, PhD

Researcher,

Hydrotreating Catalysis Team, Research Center for New Fuels and Vehicle

Technology, National Institute of Advanced Industrial Science and Technology (AIST),

1-1-1 Higashi, Tsukuba, Ibaraki 305-8565, Japan.

TEL: +81-29-861-2680

FAX: +81-29-861-4532

E-mail: sy-chen@aist.go.jp 


\section{Abstract}

Sulfonic acid-functionalized platelet SBA-15 mesoporous silica with an acid capacity of $2.44 \mathrm{mmol} \mathrm{H}^{+}$g-cat $^{-1}$ (shortly termed 15SA-SBA-15-p) was one-pot synthesized by co-condensation method. When applied as solid acid catalyst in synthesis of Jatropha biodiesel fuel (BDF), the 15SA-SBA-15-p catalyst showed higher activity and resistances to water and free fatty acid (FFA) than commercial sulfonic resins of Amberlyst-15 and SAC-13. For the continuous Jatropha BDF production, a steady $75-78 \mathrm{wt} \%$ of fatty acid methyl ester (FAME) content was obtained over 15 SA-SBA- $15-p$ catalyst at $150{ }^{\circ} \mathrm{C}$ for $75 \mathrm{~h}$, whereas the Amberlyst- 15 and SAC-13 catalysts were quickly deactivated due to the decomposition of thermally unstable framework and serious leaching of sulfonic acids. More importantly, the quality, stability and cold flow characteristic of Jatropha BDF synthesized by 15SA-SBA-15-p catalyst were better than those synthesized by Amberlyst-15 and SAC-13 catalysts, making the blending with petro-diesel an easy task.

Keywords: Biodiesel fuels, Sulfonic acid, mesopoorus silica, resistances to water and free fatty acid, regeneration, durability. 


\section{1.\# Introduction}

$\mathrm{BDF}$ is classified as a renewable transportation fuel, which has a great benefit to our living environment by lower emitting of green house and hazardous gases when compared with petro-diesel fuel (Chu and Majumdar, 2012; Melero et al., 2009). A new AEDP 2012-2021 project recently announced by the Royal Thai Government has regulated that the blending ratio of biodiesel in petro-diesel must achieve $10 \%$, i.e. B10 fuel, in 2021, corresponding to a $5.97 \mathrm{ML} /$ day market in Thailand (Department of Alternative Energy Development and Efficiency of Thailand, 2012). However, the current BDF production technology requires multiple steps using a main alkali-catalyzed transesterification unit equipped with an acid-catalyzed pre-esterification unit (Berchmans and Hirata 2008; Melero et al, 2009; Wilson and Lee, 2012). Although this conventional process can transform crude vegetable oils with acid value up to $15 \mathrm{mg} \mathrm{KOH} \mathrm{g}^{-1}$ into $\mathrm{BDF}$, the homogeneous base and acid catalysts are corrosive and difficult to be recycled, producing a vast amount of waste water, used catalysts and low-grade glycerol in addition to high cost of anti-corrosive facility. There is still room for improving BDF production technology using innovative 
solid catalysts, which are able to one-pot continuous synthesize BDF through an efficient and environmental-friendly way.

Solid acid catalysts have been applied for simultaneously catalyzing esterification of FFAs and transesterification of triglycerides, which are the main component of vegetable oils, to form BDF in the past decade (Melero et al, 2009; Suzuta et al., 2012). It can be simply classified as commercial ion exchange sulfonic resins, such as Amberlyst and Nafion families (Lopez et al., 2007), and synthesized solid acids, such as sulfonic acid-functionalized mesoporous silica and carbon (Chen et al., 2011; Liu et al., 2013), modified metal oxides (Garcia et al., 2008), heteropolyacids (Hamad et al., 2008), and metal-incorporated porous oxides (Chen et al., 2013). Because of relatively low reaction rate, the solid-acid catalyzed BDF synthesis is generally carried out at severe condition using excess amounts of catalysts and methanol (Helwani et al., 2009; Melero et al., 2009). The ion exchange sulfonic resins with polystyrene-based framework are thermally unstable at severe condition and cost ineffective. The synthesized solid acids are reported to suffer serious problems in leaching of active site or collapse of ordered porous structure (Alba-Rubio et al., 2010.). In this communication, the transesterification of crude Jatropha oil (CJO) with methanol over 15SA-SBA-15-p catalyst performed in both batch-type and fixed-bed reaction systems 
was examined for the first time, in comparison to commercial ion exchange sulfonic resins of Amberlyst-15 and SAC-13. The influences of water, FFA and regeneration on activities of these sulfonic acid-based solid acids were explored. The industrial issue on quality and cold flow characteristic of Jatropha BDF was particularly addressed, which has been rarely reported in the literature based on the best of our knowledge.

\section{2.\# Experimental}

\subsection{One-pot synthesized 15SA-SBA-15-p catalyst}

The 15SA-SBA-15-p catalyst was self-assembled in the acidic environment (Chen

et al., 2011). Prior to adding $1.40 \mathrm{~g}$ of 3-mercaptotrimethylsilane (MPTMS, Acros) as

sulfur-containing silane and $3.6 \mathrm{~g}$ of hydrogen peroxide $\left(\mathrm{H}_{2} \mathrm{O}_{2}\right.$, Wako) as in-situ

oxidizing agent, $8.4 \mathrm{~g}$ of tetraethyl orthosilicate (TEOS, Strem Chemicals) was

pre-hydrolyzed in $160 \mathrm{~g}$ of $2 \mathrm{M} \mathrm{HCl}$ synthesis solution containing $4.0 \mathrm{~g}$ of Pluronic

P123 triblock copolymer (Aldrich), $1.18 \mathrm{~g}$ of $\mathrm{NaCl}$ (Wako) and $0.64 \mathrm{~g}$ of $\mathrm{ZrOCl}_{2} \cdot 8 \mathrm{H}_{2} \mathrm{O}$

(Nakarai Chemicals). The gel composition was 0.017 P123: 1.0 TEOS: 0.15 MPTMS:

1.0 NaCl: $7.9 \mathrm{HCl}: 9.0 \mathrm{H}_{2} \mathrm{O}_{2}: 221 \mathrm{H}_{2} \mathrm{O}$. After stirred at $35^{\circ} \mathrm{C}$ for $24 \mathrm{~h}$ and 
hydrothermally treated at $100{ }^{\circ} \mathrm{C}$ for another $24 \mathrm{~h}$, the white precipitates were filtered, washed and dried at $50{ }^{\circ} \mathrm{C}$ overnight. $\mathrm{P} 123$ was removed from the as-made samples by ethanol extraction at $78{ }^{\circ} \mathrm{C}$ for $24 \mathrm{~h}$. As a result, the 15SA-SBA-15-p catalyst with a MPTMS/TEOS molar percentage of 15 was obtained.

\subsection{Reference catalysts}

Commercial ion exchange sulfonic resins of Amberlyst ${ }^{\circledR}$ 15(H), designated as

Amberlyst-15, and Nafion ${ }^{\circledR}$ SAC-13, designated as SAC-13, were purchased by Alfa Aesor and Aldrich, respectively, and used as received. Amberlyst-15 is a sulfonic acid-functionalized and macroreticular organic material based upon a styrene-divinylbenzene system. SAC-13 is an extruded silica material embedded with Nafion sulfonic resin (Lopez et al., 2007).

\subsection{Characterizations}

Small-angle XRD patterns were recorded by a Bruker AXS D8 advance diffractrometer with $\mathrm{Cu} K \alpha$ radiation $(\lambda=1.54 \AA)$ operated at $40 \mathrm{kV}$ and $40 \mathrm{~mA} . \mathrm{N}_{2}$ 
adsorption-desorption isotherms were measured by a BELSORP 28SA instrument at 77 K. Diffuse-reflectance infrared Fourier transform (DRIFT) spectra were carried out by a Thermo Nicolet Nexus 870 FT-IR instrument equipped with a small collector of in situ DRIFT cell at $100-300{ }^{\circ} \mathrm{C}$ in He flow. The sulfur contents in BDFs and solids were analyzed by a TS-100V trace sulfur analyzer and a Leco Truespec sulfur analyzer, respectively. The differential heats of $\mathrm{NH}_{3}$ adsorption were measured by a CSA-450G micro-calorimeter (Tokyo Riko, Co. Ltd., Tokyo) at $50{ }^{\circ} \mathrm{C}$. The high-resolution scanning electron microscope (HRSEM) photos were taken by a JEOL JFC-1100 field emission SEM instrument.

\subsection{Synthesis and analysis of Jatropha BDF}

Transesterification of CJO with an acid value of $4.3 \mathrm{mg} \mathrm{KOH} \mathrm{g}^{-1}$ into Jatropha BDF was carried out by a high-pressure batch-type stainless steel reactor lined with a glass tube at $200{ }^{\circ} \mathrm{C}$ for $1 \mathrm{~h}$ in $\mathrm{N}_{2}$. To start the transesterification, the stainless steel reactor containing $2.5 \mathrm{~g}(2.80 \mathrm{mmol})$ of $\mathrm{CJO}, 2.5 \mathrm{~g}(66.5 \mathrm{mmol})$ of methanol and 0.375 $\mathrm{g}$ of sulfonic acid-based solid acids was quickly inserted into a pre-heated electronic furnace with a vibration frequency of $0.5 \mathrm{~s}^{-1}$. The methanol/CJO molar ratio and the 
catalyst/CJO weight percentage were kept at 23 and 15, respectively. After the transesterification, the BDF products were analyzed by Agilent $6890 \mathrm{~N}$ GC-FID instruments based on the procedures of EN 14103:2003 and EN 14105:2003 methods (Supplemental; Suzuta et al., 2012; Chen et al., 2013). The used catalysts were regenerated by ethanol extraction at $78^{\circ} \mathrm{C}$ for 1 day. Regarding to the durability test, the Jatropha BDF synthesis over sulfonic acid-base solid acid catalysts was carried out by a fixed-bed flow reaction system at $150{ }^{\circ} \mathrm{C}$ and 5 bar using a weight hourly space

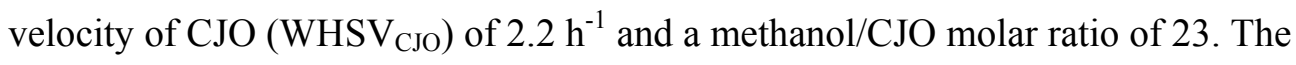
oxidation stability and cold flow characteristic of prepared Jatropha BDFs were analyzed by Metrohm 743 Rancimat and Tanaka MPC-102A instruments, respectively.

\section{Results and discussion}

\subsection{Characterizations of sulfonic acid-based solid acids}

The small-angle XRD pattern and $\mathrm{N}_{2}$ adsorption-desorption isotherm exhibit that the 15SA-SBA-15-p catalyst has three distinct diffraction peaks of (100), (110) and (200) planes in the $2 \theta$ range of $0.5-2.0^{\circ}$ and a classical type IV isotherm with a steep 
$\mathrm{H}_{1}$ hysteresis in a relative high $P / P_{0}$ range of $0.6-0.8$, indicating the presence of well-ordered 2D hexagonal $p 6 \mathrm{~mm}$ structure with largely channeling pores (Zhao et al., 1998; Supplemental Fig. S1). Regarding to Amberlyst-15 and SAC-13 catalysts, X-ray amorphous frameworks with ultra-large and disordered mesopores are confirmed (Supplemental Fig. S2).

From the optic and HRSEM photos, the 15SA-SBA-15-p catalyst in the form of white powder has platelet morphology with $1-1.5 \mu \mathrm{m}$ in width and 200-350 $\mathrm{nm}$ in thickness (Supplemental S3 and S4). The previous study had exhibited that the mesochannels are parallel to the short axis of the platelet (Chen et al., 2011). The molecular diffusion through shortly channeling pores of 15SA-SBA-15-p catalyst can be facilitated when applying it in catalysis. By contrast, the Amberlyst-15 and SAC-13 catalysts constructed from a lot of irregular nanoparticles are spherical balls and extruded rods in the millimeter scale (Supplemental Fig. S3 and S4).

Table 1 shows that the 15SA-SBA-15 catalyst possesses high surface area $\left(\mathrm{S}_{\mathrm{BET}}\right)$ of $589 \mathrm{~m}^{2} \mathrm{~g}^{-1}$, large pore volume $\left(\mathrm{V}_{\text {Total }}\right)$ of $0.96 \mathrm{~cm}^{3} \mathrm{~g}^{-1}$, and well-ordered mesopores with pore diameter $\left(\Phi_{\mathrm{p}}\right)$ of $7.5 \mathrm{~nm}$. The SAC-13 catalyst with porous silica framework has moderate $S_{\mathrm{BET}}$ and $\mathrm{V}_{\mathrm{p}}$ values of $215 \mathrm{~m}^{2} \mathrm{~g}^{-1}$ and $0.57 \mathrm{~cm}^{3} \mathrm{~g}^{-1}$, respectively. The Amberlyst-15 catalyst with densely organic framework gives lowest $S_{B E T}$ and $V_{p}$ 
values of $21 \mathrm{~m}^{2} \mathrm{~g}^{-1}$ and $0.32 \mathrm{~cm}^{3} \mathrm{~g}^{-1}$, respectively. Note that the large $\Phi_{\mathrm{p}}$ values (57-72 $\mathrm{nm})$ of SAC-13 and Amberlyst-15 catalysts are originated from the aggregation voids of irregular nanoparticles, which are supported by the results of HRSEM photos.

The acid property of three catalysts was thoroughly examined by $\mathrm{NH}_{3}$ chemisorption equipped with a micro-calorimeter (Figure 1) and DRIFT spectroscopy with pyridine adsorption (Supplemental Figure S5). The acid capacity decreases in the order of Amberlyst-15 (4.50 mmol H${ }^{+}$g-cat $\left.{ }^{-1}\right)>15 \mathrm{SA}-\mathrm{SBA}-15-\mathrm{p}(2.44 \mathrm{mmol} \mathrm{H}$ g-cat $\left.^{-1}\right)>$ SAC-13 $\left(1.35 \mathrm{mmol} \mathrm{H}^{+}\right.$g-cat $\left.^{-1}\right)$, and their acidic nature is mostly related to Bronsted acid. According to the classification of the differential heat of $\mathrm{NH}_{3}$ adsorption, the 15SA-SBA-15-p catalyst contains $1.49 \mathrm{mmol} \mathrm{H}^{+}$g-cat ${ }^{-1}$ of weakly acidic site and $0.962 \mathrm{mmol} \mathrm{H}^{+}$g-cat ${ }^{-1}$ of strongly and moderately acidic sites (Supplemental Table S1). The latter is similar with the sulfonic acid loading of 1.10 mmol g-cat ${ }^{-1}$ in 15 SA-SBA-15-p catalyst as determined by sulfur analysis. It suggests that the strongly and moderately acidic sites are originated from propylsulfonic acids whereas the weakly acidic sites should have to do with the surface silanol groups (Liu et al. 2013; Chen et al. 2013). As to the SAC-13 catalyst, the amount of weakly acidic sites is $0.91 \mathrm{mmol} \mathrm{H}^{+}$g-cat ${ }^{-1}$, which corresponds to a large number of silanol groups on porous silica framework, whereas the sum of strongly and moderately acidic sites are 
only $0.444 \mathrm{mmol} \mathrm{H}^{+}$g-cat ${ }^{-1}$, due to a few amounts of fluorosulfonic acid groups on Nafion resin. By contrast, most of acidic sites in Amberlyst-15 are classified as strongly acidic site $\left(4.26 \mathrm{mmol} \mathrm{H}^{+} \mathrm{g}-\mathrm{cat}^{-1}\right)$, which corresponds to a large number of phenyl sulfonic acid groups.

\subsection{Synthesis of Jatropha BDF over sulfonic acid-based solid acids}

The transesterification of CJO with methanol was carried out at $200{ }^{\circ} \mathrm{C}$ for $1 \mathrm{~h}$ under autogeneous pressure. Table 1 shows that the FAME contents increase in the order of SAC-13 (45.4 wt $\%)<$ Amberlyst-15 (70.0 wt $\%)<15$ SA-SBA-15-p (82.6 $\mathrm{wt} \%$ ) whereas the FFA and $\mathrm{T}_{\text {glycerol }}$ values give an opposite trend. The blank test only gives $15.1 \mathrm{wt} \%$ of FAME content under the same reaction condition. Evidently, the catalytically active sites for Jatropha BDF synthesis are mainly related to the sulfonic acid groups. The highest FAME content over 15SA-SBA-15-p catalyst is attributed to

fully accessible sulfonic acids on the surfaces of shortly channeling pores. The lowest FAME content over SAC-15 catalyst is attributed to a small amount of sulfonic acid groups. An abnormal amount of FFAs over Amberlyst-15 catalyst suggests that the strongly acidic site is favorable for dehydration of methanol into water and dimethyl 
ether, and subsequent hydrolysis of TG with water into unwanted byproducts of FFAs, diglycerides and monglycerides. Note that the catalytically active sites of sulfonic acid groups can be significantly poisoned by adsorption of water, causing relatively low FAME content over Amberlyst-15 catalyst. Fortunately, the side reaction and water poison can be suppressed over 15SA-SBA-15-p catalyst with proper acidity and hydrophilic surface, which is a good medium for water adsorption (Chen et al., 2013.). Figure 2 shows the influences of lauric acid (LA), $\mathrm{H}_{2} \mathrm{O}$ and regeneration on activities of 15SA-SBA-15-p, SAC-13 and Amberlyst-15 catalysts in Jatropha BDF synthesis at $200{ }^{\circ} \mathrm{C}$ for $1 \mathrm{~h}$. When $50 \mathrm{wt} \%$ of LA is added in the reaction medium, the FAME content over 15SA-SBA-15-p catalyst is almost unchanged and the LA conversion is $95.5 \%$ (Supplemental Table S2). By contrast, the decrease in FAME contents over SAC-13 and Amberlyst-15 catalysts increase to $2.0-3.5 \%$ and the LA conversion over Amberlyst- 15 catalyst is only $62.3 \mathrm{wt} \%$. When $5 \mathrm{wt} \%$ of $\mathrm{H}_{2} \mathrm{O}$ is added to the reaction medium, the decrease in FAME content over 15SA-SBA-15-p is 4.6 wt $\%$ but those over Amberlyst-15 and SAC-13 catalysts are extended to 7.4 and 9.0 $\mathrm{wt} \%$, respectively. Regarding to the regeneration treatment, the decrease in FAME content over regenerated $15 \mathrm{SA}-\mathrm{SBA}-15$-p catalyst is only $3.6 \mathrm{wt} \%$, associated with a little leaching of sulfonic acids during the reaction and regeneration processes 
(supplemental Table S2). By contrast, the FAME contents over regenerated Amberlyst-15 and SAC-13 catalysts are significantly decreased around 5.0-10.4 wt\% due to serious leaching of sulfonic acids.

Figure 3 further compares the durability of 15SA-SBA-15-p catalyst in Jatropha BDF synthesis with SAC-13 and Amberlyst-15 catalysts studied by a fixed-bed flow reaction system at $150{ }^{\circ} \mathrm{C}$ and 5 bar. Since the sulfonic acids are relatively stable in mesoporous silica framework, the FAME content over 15SA-SBA-15-p catalyst is kept at around $75-78 \mathrm{wt} \%$ even after the time on stream is more than $75 \mathrm{~h}$. By contrast, the FAME contents over Amberlyst-15 and SAC-13 catalysts significant decrease from $49-51 \mathrm{wt} \%$ at the beginning of the reaction to $27-31 \mathrm{wt} \%$ for the time on stream of around $75 \mathrm{~h}$ due to the carbonization of thermally unstable organic framework, formation of cokes and serious leaching of sulfonic acids (Alba-Rubio et al., 2010; supplemental Figures S6). It is specially noticed that the quality, oxidation stability and cold flow characteristic of Jatropha BDF synthesized by 15SA-SBA-15-p catalyst are better than those by Amberlyst-15 and SAC-13 catalysts, probably due to minimizing side reactions, such as polymerization of polyunsaturated FAMEs and formation of unwanted FFAs during the continuous Jatropha BDF production (Table 2). In other words, the Jatropha BDF synthesized by 15SA-SBA-15-p catalyst should be directly 
blended to a large extent with petro-diesel. Based on the catalytic study, it can be said that the 15SA-SBA-15-p catalyst is the most efficient, robust and reusable sulfonic acid-based solid acid for simultaneous esterification of FFAs and transesterification of triglycerides into high-quality BDF products.

\section{Conclusions}

The propylsulfonic acid-functionalized SBA-15 mesoporous silica with platelet morphology and short channeling pores, i.e. 15SA-SBA-15-p, has been applied as a solid acid catalyst for Jatropha BDF synthesis in batch-type and fixed-bed reaction systems. Compared with commercial ion exchange sulfonic resins of Amberlyst-15 and SAC-13, the 15SA-SBA-15-p catalyst gave higher activity, better water and FFA tolerance levels, and longer durability for the production of high-quality Jatropha BDF with suppressing of the side reactions and coke formation, due to that the sulfonic acids were stably incorporated in fully accessible, thermally stable and hydrophilic channeling pores in 200-350 $\mathrm{nm}$.

\section{Acknowledgements}


The financial support from JST-JICA's SATREPS project is gratefully acknowledged.

Acknowledgements are extended to Dr. A. Endo and Dr. A. Kawai of Research

Institute for Innovation in Sustainable Chemistry, AIST, for XRD measurement. 


\section{References:}

1. Alba-Rubio, A.C., Vila, F., Artin Alonso, D., Ojeda, M., Mariscal, R., Lopez

Granados, M., 2010, Deactivation of organosulfuric acid functionalized silica catalysts during biodiesel synthesis. Appl. Catal. B:Environ. 95, 279-287.

2. Berchmans, H. J., Hirata, S., 2008. Biodiesel production from crude Jatropha curcas L. seed oil with a high content of free fatty acids. Bioresource Technology 99, 1716-1721.

3. Chen, S.Y., Yokoi, T., Tang, C.Y., Jang, L.Y., Tatsumi, T., Chan, J.C.C., Cheng, S., 2011. Sulfonic acid-functionalized platelet SBA-15 materials as efficient catalysts for biodiesel synthesis. Green. Chem. 13, 2920-2930.

4. Chen, S.Y., Mochizuki, T., Abe, Y., Toba, M., Yoshimura, Y., 2013. Production of high-quality biodiesel fuels from various vegetable oils over Ti-incorporated SBA-15 mesoporous silica. Catal. Commun. 41, 136-139.

5. Chu, S., Majumdar, A., 2012. Opportunities and challenges for a sustainable energy future. Nature 488, 294-303.

6. Department of Alternative Energy Development and Efficiency of Thailand, 2012. The Renewable and Alternative Energy Development Plan for 25 Percent in 10 Years (AEDP 2012-21). 
www.dede.go.th/dede/images/stories/dede_aedp_2012_2021.pdf, (accessed

September 11, 2013).

7. Garcia, C.M., Teixeira, S., Marciniuk, L.L., Schuchardt, U., 2008.

Transesterification of soybean oil catalyzed by sulfated zirconia. Bioresour.

Technol. 99, 6608-6613.

8. Hamad, B., Lopes de Souza, R.O., Sapaly, G., Carneiro Rocha, M.G., Pries de

Oliveira, P.G., Gonzalez, W.A., Andrade Sales, E., Essayem, N., 2008.

Transesterification of rapeseed oil with ethanol over heterogeneous

heteropolyacids. Catal. Commun. 10, 92-97.

9. Helwani, Z., Othman, M.R., Aziz, N., Fernando, W.J.N., Kim, J., 2009.

Technologies for production of biodiesel focusing on green catalytic techniques: A review. Fuel Processing Tech. 90, 1502-1514.

10. Liu, T., Li, Z., Li, W., Shi, C., Wang, Y., 2013. Preparation and characterization of biomass carbon-based solid acid catalyst for the esterification of oleic acid with methanol. Bioresour. Technol. 133, 618-621.

11. Lopez, D. E., Goodwin Jr, J.G., Bruce, D.A., 2007. Transesterification of triacetin with methanol on Nafion acid resins. J. Catal. 245, 381-391. 
12. Melero, J.A., Iglesias, J., Morales, G., 2009. Heterogeneous acid catalysts for biodiesel production: current status and future challenges. Green Chem. 11, $1285-1308$.

13. Suzuta, T., Toba, M., Abe, Y., Yoshimura, Y., 2012. J. Am. Oil. Chem. Soc. 89, 1981-1989.

14. Wilson, K., Lee, A.F., 2012. Rational design of heterogeneous catalysts for biodiesel synthesis. Catal. Sci. Technol. 2, 884-897.

15. Zhao, D., Feng, J., Huo, Q., Melosh, N., Frederichson, G. H., Chmelka, B. F., Stucky, G. D., 1998. Triblock copolymer syntheses of mesoporous silica with periodic 50 to 300 angstrom pores. Science. $279,548-552$. 
Table 1. Physicochemical properties of 15SA-SBA-15-p, SAC-13 and Amberlyst-15 catalysts and their catalytic activities in Jatropha BDF synthesis. ${ }^{\text {a }}$

\begin{tabular}{|c|c|c|c|c|c|c|c|}
\hline Catalysts & $\begin{array}{l}S_{B E T} \\
\left(\mathbf{m}^{2} g^{-1}\right)\end{array}$ & $\begin{array}{l}V_{\text {Total }} \\
\left(\mathrm{cm}^{3} \mathrm{~g}^{-1}\right)\end{array}$ & $\begin{array}{l}\Phi_{\mathrm{p}} \\
(\mathrm{nm})\end{array}$ & $\begin{array}{l}\text { Acid Capacity }^{\mathbf{b}} \\
\left(\mathrm{mmol} \mathrm{H}^{+} \text {g-catal }^{-1}\right)\end{array}$ & $\begin{array}{l}\text { FAME } \\
(w t \%)\end{array}$ & $\begin{array}{l}\text { FFA }^{c} \\
(w t \%)\end{array}$ & $\begin{array}{l}T_{\text {glycerol }}{ }^{c} \\
(\mathbf{w t} \%)\end{array}$ \\
\hline None & - & - & - & - & 15.1 & 4.2 & 9.7 \\
\hline 15SA-SBA-15-p & 589 & 0.96 & 7.5 & 2.44 & 82.6 & 5.9 & 1.8 \\
\hline Amberlyst-15 & 21 & 0.32 & 72 & 4.50 & 70.0 & 25 & 0.75 \\
\hline SAC-13 & 215 & 0.57 & 57 & 1.35 & 45.4 & 7.4 & 6.0 \\
\hline
\end{tabular}

a Reaction condition: $200{ }^{\circ} \mathrm{C}$ for $1 \mathrm{~h}$ under autogenously pressure, $2.5 \mathrm{~g}$ (2.80 mmol) of CJO, $2.13 \mathrm{~g}$ (66.5 mmol) of methanol, $0.375 \mathrm{~g}$ of catalyst ( $15 \mathrm{wt} \%$ of CJO).

b Based on the results of $\mathrm{NH}_{3}$ chemisorption.

c $\quad$ Based on the procedures of EN 14103 and 14105 methods. 
Table 2. The quality, oxidation stability and cold flow properties of Jatropha BDFs over 15SA-SBA-15-p, Amberlyst-15 and SAC-13 catalysts using a fixed-bed flow reaction system. ${ }^{a}$

\begin{tabular}{|c|c|c|c|c|c|c|}
\hline Catalysts & $\begin{array}{l}\text { FAME } \\
\text { (wt \%) }\end{array}$ & $\begin{array}{l}\text { FFA } \\
(w t \%)\end{array}$ & $\begin{array}{l}T_{\text {glycerol }} \\
\text { (wt\%) }\end{array}$ & $\begin{array}{l}\text { Oxidation Stability } \\
\text { (h) }\end{array}$ & $\begin{array}{l}\text { Cloud Point } \\
\left({ }^{\circ} \mathrm{C}\right)\end{array}$ & $\begin{array}{l}\text { Pour Point } \\
\left({ }^{\circ} \mathrm{C}\right)\end{array}$ \\
\hline 15SA-SBA-15-p & 75.0 & 4.6 & 3.1 & 2.0 & 10 & 3 \\
\hline Amberlyst-15 & 31.4 & 4.8 & 7.7 & 1.7 & 21 & 0 \\
\hline SAC-13 & 27.6 & 5.5 & 8.2 & 1.3 & 23 & 1 \\
\hline
\end{tabular}




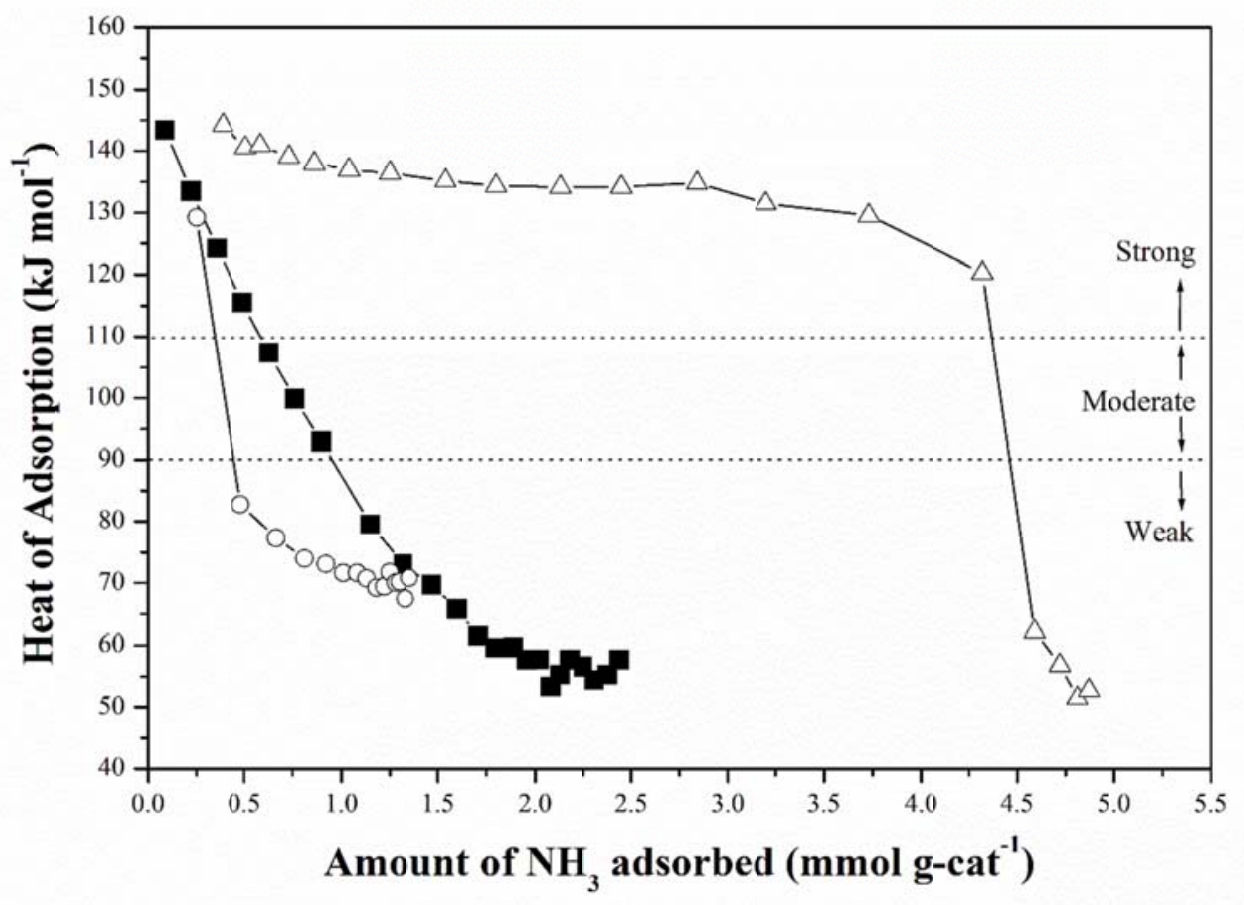

Figure 1. Differential heat of $\mathrm{NH}_{3}$ adsorbed over (घ) 15SA-SBA-15, $(\triangle$ ) Amberlyst-15 and (०) SAC-13 catalysts recorded at $50{ }^{\circ} \mathrm{C}$. 


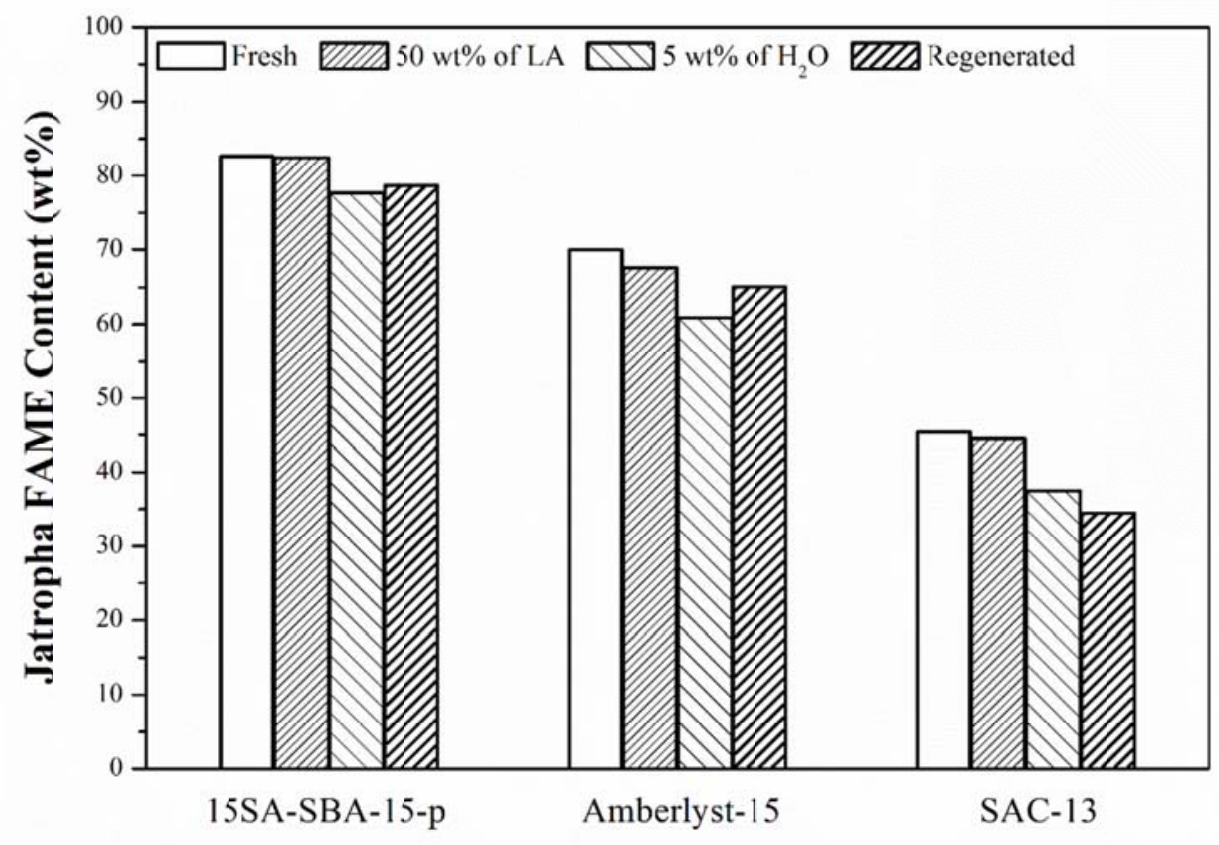

Figure 2. Influences of $\mathrm{LA}, \mathrm{H}_{2} \mathrm{O}$ and regeneration on activities of 15SA-SBA-15-p, Amberlyst-15 and SAC-13 catalysts in Jatropha BDF synthesis at $200{ }^{\circ} \mathrm{C}$ for $1 \mathrm{~h}$. 


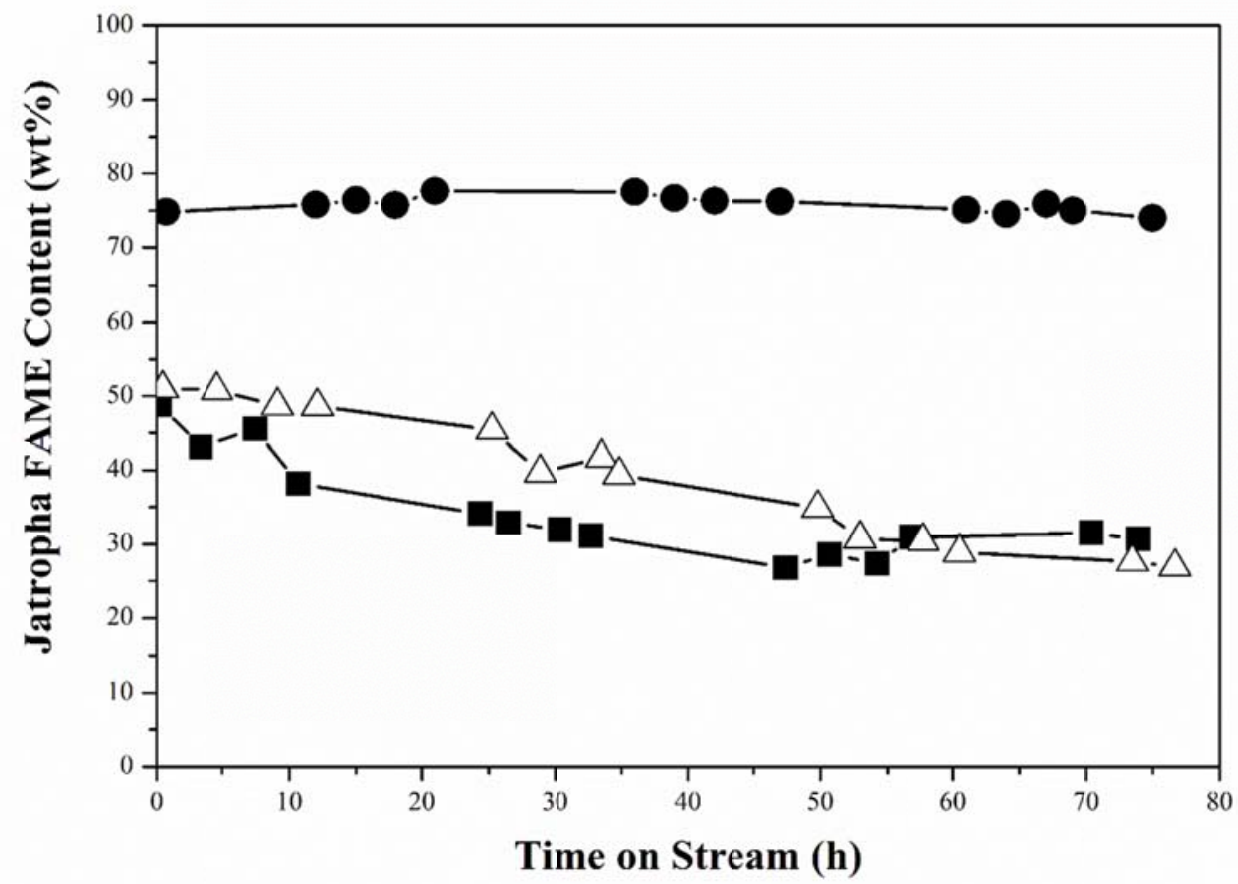

Figure 3. Jatropha BDF content as a function of time on stream over $(\bullet)$ 15SA-SBA-15,

(a) Amberlyst-15 and $(\triangle)$ SAC-13 catalysts obtained in a fixed-bed flow reaction system operating at $150{ }^{\circ} \mathrm{C}$ and 5 bar using a WHSV CJO value of $2.2 \mathrm{~h}^{-1}$ and a methanol/CJO molar ratio of 23 . 